\title{
Analisa Kebutuhan E-commerce untuk UKM Menggunakan Goal- Oriented Requirement Engineering (GORE)
}

\author{
Noor Falih \\ Program Studi Informatika \\ Fakultas Ilmu komputer, Universitas Pembangunan Nasional Veteran Jakarta \\ falih@upnvj.ac.id
}

\begin{abstract}
Abstrak. Rekayasa kebutuhan berorientasi pada tujuan memberikan mekanisme yang sesuai untuk memahami kebutuhan aplikasi E-commerce yang diinginkan oleh pelanggan, yaitu UKM dan pembina UKM. KAOS adalah salah satu teknik pemodelan berorientasi pada tujuan yang menghasilkan kebutuhan yang lebih spesifik dan lebih mudah ditelusuri. Salah satu faktor yang menyebabkan E-commerce ditinggalakan oleh penjual dalam hal ini UKM, adalah tidak adanya akses pembiayaan dan pembinaan (seperti pendampingan/pelatihan, monitoring dan penilaian perbaikan) karena pembiayaan dan pembinaan adalah salah satu faktor kunci kesuksesan dan kegagalan suatu UKM. Penelitian ini membahas tentang model kebutuhan perangkat lunak E-commerce yang sesuai untuk UKM. Pembuatan model diawali dengan melakukan studi literature dan wawancara dengan UKM Center Universitas Universal sehingga menghasilkan tujuan (Goal) yang masih umum. Tujuan tersebut kemudian diturunkan menjadi beberapa sub-tujuan menggunakan pemodelan KAOS sehingga menghasilkan kebutuhan fungsional dan kebutuhan nonfungsional. Hasil penelitian ini menunjukkan bahwa pemodelan kebutuhan dengan menggunakaan KAOS dapat digunakan dalam memodelkan kebutuhan untuk aplikasi E-commerce yang sesuai dengan tujuan UKM dengan menghasilkan kebutuhan yang valid.
\end{abstract}

Kata kunci: Kebutuhan, E-commerce, GORE.

\section{Pendahuluan}

Pengadaan perangkat lunak pada sebuah perusahaan hampir menjadi hal yang rutin dilakukan. Pentingnya perangkat lunak sebagai tools yang sangat bermanfaat untuk membantu pekerjaan pada sebuah perusahaan mulai disadari. Tetapi tidak semua perangkat lunak tersebut pada akhirnya akan digunakan dengan baik atau bahkan tidak digunakan sama sekali.

E-commerce adalah satu set dinamis teknologi, perangkat lunak, dan proses bisnis yang menghubungkan perusahaan, konsumen, dan komunitas tertentu melalui transaksi elektronik dan perdagangan barang, pelayanan, dan informasi yang dilakukan secara elektronik [1]. Salah satu jenis E-commerce yang banyak digunakan oleh UKM di Indonesia adalah B2C (Bussines to Consummer).

Namun ditengah peningkatan penggunaan E-commerce, banyak juga E-commerce yang mulai ditinggalkan / tidak digunakan oleh penggunanya terutama oleh ukm, sehingga menyebabkan satu per satu harus tutup seperti lamido, valadoo, sedapur, paraplou, wearfable. Dari data yang diperoleh, tingkat kepercayaan pengguna Internet Indonesia terhadap B2C sistem E-commerce di Indonesia hanya 66\% [2]. Hal tersebut menunjukkan bahwa $E$ commerce dibangun pada perusahaan tersebut tidak memberikan rasa aman dan nyaman kepada pelanggan dalam melakukan transaksi, sehingga E-commerce tersebut tidak terpakai dan dianggap gagal.

Selain faktor diatas yang lebih dominan dirasakan oleh pembeli, hal yang menyebabkan E-commerce ditinggalakan oleh penjual dalam hal ini UKM, adalah tidak adanya akses pembiayaan dan pendampingan (seperti pembinaan/pelatihan, monitoring dan penilaian perbaikan) karena pembiayaan dan pendampingan adalah salah satu faktor kunci kesuksesan dan kegagalan suatu UKM [3]. Perangkat lunak dalam hal ini E-commerce bagi UKM menjadi tidak terpakai dapat disebabkan karena salah sasaran, tidak sesuai spesifikasi, atau tidak mendapatkan respons yang sesuai dari pengguna (pembeli dan UKM). 
Pada perkembangan penelitian dalam kebutuhan perangkat lunak, sudah banyak dilakukan penelitian kebutuhan perangkat lunak untuk E-commerce [4] [5] maupun penelitian tentang GORE [6]. Namun belum ditemukan penelitian yang menekankan pada aspek kebutuhan pengguna dalam hal ini UKM dengan menggunakan pendekatan GORE (Goal Oriented Requirement Engineering). Dengan demikian pendekatan tersebut juga belum dapat dibuktikan apakah dapat digunakan sebagai metode atau dapat dikembangkan untuk menangani kebutuhan E-commerce bagi UKM .

Penelitian ini menggunakan pendekatan GORE untuk menggali kebutuhan dari stakeholder. GORE berbeda dengan rekayasa kebutuhan tradisional. Model pengembang perangkat lunak tradisional hanya memodelkan kebutuhanya saja, akan tetapi GORE juga memodelkan tujuannya (Goal). Goal itulah alasan sebenarnya mengapa kebutuhan itu dibutuhkan [6].

Ada beberapa teknik pemodelan yang menggunakan pendekatan GORE seperti KAOS (Knowledge Acquisition in autOmated Specification), I*, dan TROPOS. Namun teknik pemodelan KAOS dan I* yang paling sering digunakan dalam penelitian [7]. Dan teknik pemodlean KAOS lebih baik jika dibandingkan dengan I*, karena KAOS lebih sederhana dan berfokus menghasilkan kebutuhan yang lebih spesifik dan lebih mudah ditelusuri $[10][8]$.

Penelitian ini diharapkan menghasilkan model kebutuhan yang merasionalisasikan berbagai kebutuhan yang diperlukan oleh sebuah sistem yang akan dibuat berdasarkan dari tujuan-tujuan yang dirumuskan, bukan hanya berdasarkan data dan proses bisnis manual.

\section{Tinjauan Pustaka}

Rekayasa kebutuhan adalah fase terdepan dari proses rekayasa perangkat lunak, dimana kebutuhan dari pengguna dan pelanggan dikumpulkan, dipahami dan ditetapkan. GORE (Goal-Oriented Requirement Engineering) adalah salah satu teknik dalam rekayasa kebutuhan yang sangat sering digunakan [9].

Rekayasa kebutuhan merupakan fase terdepan dari proses rekayasa perangkat lunak, dimana kebutuhan dari pengguna dan pelanggan dikumpulkan, dipahami dan ditetapkan. Rekayasa kebutuhan adalah suatu pekerjaan yang sangat penting. Fakta membuktikan bahwa kebanyakan kegagalan pengembangan perangkat lunak disebabkan karena adaya ketidakkonsistenan (inconsistent), ketidaklengkapan (incomplete), maupun ketidakbenaran (incorrect) dari spesifikasi kebutuhan.

Kebutuhan pada sebuah proyek pengembangan perangkat lunak digunakan untuk :
1. Spesifikasi (Specification)
2. Perencanaan (Planning)
3. Pengembangan (Development)
4. Evaluasi (Evaluation)

Jika kebutuhan tidak dinyatakan dengan jelas, pengembang perangkat lunak bisa saja memandang, menginterpretasikan, mengimplementasikan dan mengevaluasi secara berbeda satu sama lain. Hal ini dapat menyebabkan perangkat lunak yang tidak konsisten dengan ekspektasi pengguna, memiiki kualitas yang buruk karena memicu ketidakpuasan stakeholders dan membuang waktu dan biaya pengerjaan perangkat lunak.

GORE (Goal-Oriented Requirement Engineering) adalah salah satu teknik dalam rekayasa kebutuhan yang sangat sering digunakan [9]. Hal ini disebabkan karena ketidakmampuan teknik rekayasa kebutuhan tradisional dalam menangani rekayasa perangkat lunak yang semakin kompleks. Rekayasa kebutuhan tradisional lebih kepada menggali keinginan pengguna tentang sistem seperti apa yang akan dibuat. Tujuan dari rekayasa kebutuhan tradisional adalah untuk menghasilkan sebuah dokumen kebutuhan yang akan diberikan ke programmer. Hal ini dilakukan agar sistem yang dibangun sesuai dengan spesifikasi dan batasan yang ditentukan. Tapi, rekayasa kebutuhan tradisional hanya fokus pada system seperti apa yang harus dibuat dan tidak fokus pada "mengapa" sistem tersebut dibuat. 
GORE berbeda dengan rekayasa kebutuhan tradisional. Model pengembang perangkat lunak tradisional hanya memodelkan kebutuhanya saja, akan tetapi GORE juga memodelkan tujuannya (Goal). Goal itulah alasan sebenarnya mengapa kebutuhan itu dibutuhkan.

\subsection{KAOS}

KAOS adalah pendekatan rekayasa kebutuhan yang berorientasi pada tujuan. KAOS, menurut Lamsweerde [9], berarti Keep All Objects Satisfied. Metode ini dianggap sebagai model multi-paradigma yang memungkinkan kombinasi berbagai tingkat ekspresi dan rasional: semiformal untuk pemodelan dan penataan tujuan, kualitatif untuk pilihan alternatif dan formal untuk elemen kritis. Secara umum, pemodelan KAOS memiliki lapisan semantik grafis eksternal dengan konsep, atribut dan hubungan dan lapisan formal internal yang dibantu oleh logika temporal. Konvensi diagram KAOS dapat dilihat pada gambar 1.

Elemen pada KAOS [10] meliputi istilah berikut ini:

$>$ Tujuan (goal) didefinisikan sebagai kumpulan perilaku / keadaan yang harus dipenuhi atau dapat diterima oleh sistem dalam sebuah kondisi yang ditetapkan [9]. Definisi goal harus jelas sehingga dapat diverifikasi apakah sistem mampu memenuhi / memuaskan goal tersebut.

$>$ Softgoal digunakan untuk mendokumentasikan perlaku alternatif dari sistem, sehingga tidak secara tegas dapat diverifikasi tingkat kepuasannya. Tingkat kepuasan dari softgoal akan dibatasi menggunakan limitasi yang ditetapkan.

$>$ Agen (agents) adalah sebuah jenis dari obyek yang bertindak sebagai pemroses kegiatan operasional. Agen merupakan komponen aktif bisa berupa manusia, perangkat keras, perangkat lunak, dan lainnya yang mempunyai peran spesifik dalam memuaskan sebuah tujuan.
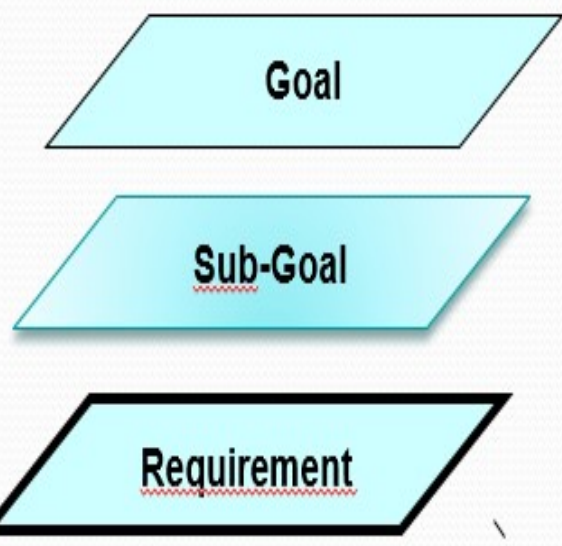

Agent

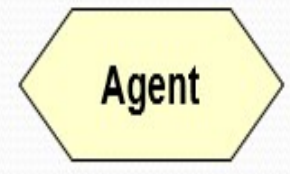

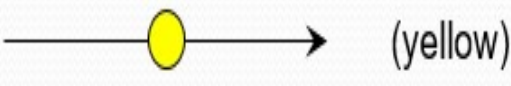

penvempurnaan tujuan
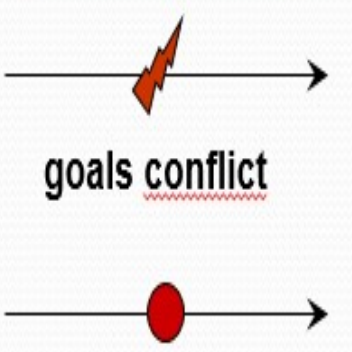

(red)

Tanggung jawab

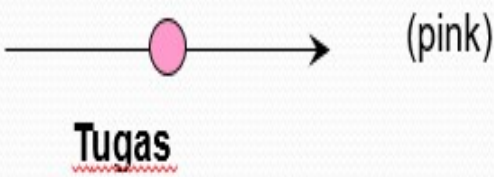

Gambar 1. Konvensi diagram KAOS

Ada 3 jenis ketergantungan diantara goal pada KAOS [10], yaitu :

$>$ AND/OR-decomposition yaitu sebuah hubungan yang menggambarkan hirarki dari goal dengan subgoal-nya, menggambarkan bahwa goal dapat dipenuhi/dipuaskan jika seluruh sub-goal-nya 
terpuaskan (menggunakan AND decomposistion), atau minimal salah satu dari softgoal tersebut terpuaskan (menggunakan OR decomposistion).

$>$ Potential conflict yaitu hubungan yang menggambarkan pada kondisi tertentu, jika sebuah goal terpenuhi ternyata dapat menyebabkan goal yang lainnya tidak terpenuhi. Konflik ini biasanya bisa muncul karena adanya perbedaan sudut pandang dan kepentingan dari entitas yang berhubungan [9].

$>$ Responsibility assignment yaitu hubungan antara agen dengan sebuah goal. Agen yang terhubung tersebut mempunyai tanggung jawab agar goal dapat dipenuhi/terpuaskan.

KAOS terdiri dari empat model, yaitu Goal Model, Responsibility Model, Object Model dan Model Operasional.

Goal model adalah model yang terdiri dari tujuan, subgoal, ekspektasi, kebutuhan, properti domain, agen, konflik, dan hambatan. Goal Model dirancang dengan konsep topdown dan hierarkis. Goal dapat merujuk ke layanan (tujuan fungsional) atau kualitas layanan (tujuan non-fungsional). Setiap sub-goal berasal dari goal lain yang menjelaskan "mengapa" sub-goal diperlukan. Dengan kata lain, sub-goal menjelaskan "bagaimana" untuk mencapai tujuan di atasnya. Kebutuhan dan harapan akan diperoleh pada tingkat yang lebih rendah dari model dan harus ditugaskan ke agent.

Responsibility Model menggambarkan tanggung jawab agen terhadap kebutuhan dan ekspektasi. Object Model adalah model yang menyatakan objek yang menarik dalam domain aplikasi, yang akan dibangun [11]. Model ini bisa berupa entitas, hubungan, event, atau agen. Objek ini berasal dari spesifikasi tujuan dalam model sasaran dan karakteristiknya dinyatakan sebagai atribut. Model terakhir adalah model Operasional. Model ini menjelaskan perilaku yang diperlukan agen untuk mencapai kebutuhanya.

\subsection{E-commerce untuk UKM}

E-commerce menurut David Baum [1] yaitu satu set dinamis teknologi, aplikasi, dan proses bisnis yang menghubungkan perusahaan, konsumen, dan komunitas tertentu melalui transaksi elektronik dan perdagangan barang, pelayanan, dan informasi yang dilakukan secara elektronik. Salah satu jenis E-commerce adalah B2C (Bussines to Consummer ) yaitu bisnis yang melakukan pelayanan atau penjualan barang atau jasa kepada konsumen perorangan atau grup secara langsung.

Salah satu aktifitas dalam proses pengembangan perangkat lunak adalah analisa kebutuhan perangkat lunak, proses pertama kali yang dilakaukan dalam analisa kebutuhan perangkat lunak adalah insepsi, dan salah satu aktifitas insepsi adalah mengidentifikasi stakeholder, banyak penelitian yang menyatakan bahwa stakeholder utama dari E-commerce jenis B2c adalah konsumen [2] sehingga kebutuhan perangkat lunak yang dihasilkan untuk konsumen saja. Padahal penjual dan pemilik E-commerce juga termasuk pemangku kepentingan utama. Dan juga penjual E-commerce di Indonesia didominasi oleh pelaku UKM yang masih membutuhkan pendampingan dalam usahanya.

Usaha kecil dan Menengah (UKM) yang didefinisikan sebagai independen produktif di Indonesia, berikontribusi terhadap pengurangan tingkat kemiskinan dan pengangguran di Indonesia [13]. Namun kemampuan dalam berkompetisi di dalam era global tentu sangat kecil jika dibandingkan dengan perusahaan-perusahaan besar. Dengan memanfaatkan E-commerce para pengusaha UKM mencoba berkompetisi, walapun angka penerapan masih rendah dan juga terdapat perbedaan tingkat penerapan di setiap UKM.

Model kebutuhan E-commerce yang melibatkan tidak hanya melibatkan tujuan/goal dari konsumen, namun juga melibatkan UKM, dan Pembina UKM ini bukan hanya dapat memecahkan sebagian atau bahkan keseluruhan permasalahan konsumen saja, namun permasalahan UKM juga turut terakomodir. Di antaranya problematika maupun kekhasan UKM yang tidak memiliki akses pinjaman perbankan atau tidak bankable, yang menghalangi kemampuan akses pasar yang lebih besar.

Pemerintah Indonesia melalui kementerian komunikasi dan informatika (KOMINFO) membuat peta jalan yang dinamai blue-print roadmap E-commerce [14]. Peta jalan itu mencakup 7 aspek strategis yakni logistik, pendanaan, perlindungan konsumen, infrastruktur komunikasi, perpajakan, pengembangan Sumber Daya Manusia (SDM), serta keamanan siber (cyber security). Perlindungan konsumen dan keamanan dan logistik lebih 
menyasar kepada faktor kepercayaan dan kepuasan konsumen, pendanaan lebih ke pelaku UKM, sedangkan pengembangan Sumber Daya Manusia lebih ke Pembinaan UKM.

\section{Metodologi}

Metodologi yang digunakan dalam penelitian ini adalah metode Concept Implementation dengan melakukan beberapa pendekatan seperti pada gambar 2 .

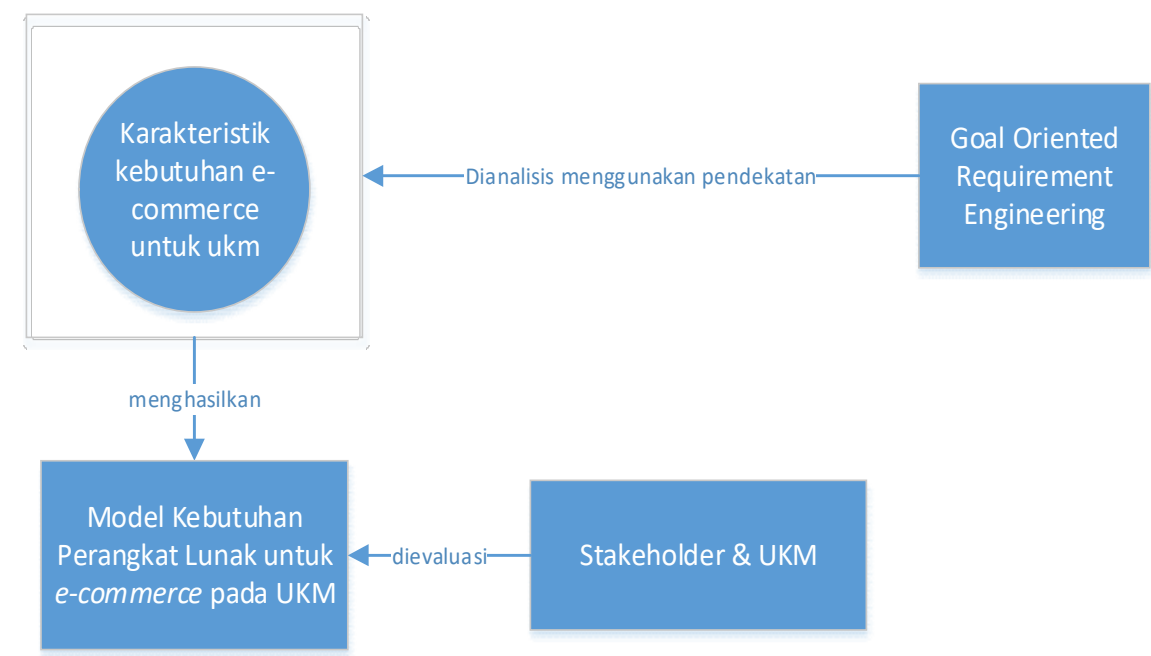

Gambar 2. Metode Pembuatan model kebutuhan E-commerce pada UKM

1. Studi literatur

Studi literatur dilakukan dengan mengumpulkan berbagai literatur yang berkaitan dengan requirement engineering, ukm, ISO/IEC 25030 dan GORE (Goal Oriented Requirement Engineering).

2. Survey

Survey dalam hal ini dilakukan untuk mengetahui berapa banyak E-commerce untuk ukm, mengapa perangkat lunak tersebut bisa gagal dan mengapa perangkat lunak tersebut bisa dipakai. faktor apa saja yang dibutuhkan oleh stakeholder dari E-commerce (UKM, dan Pembeli ).

3. Analisa \& Pemodelan Kebutuhan

Dari hasil studi literatur, akan dirumuskan apa saja yang menjadi kriteria kualitas dari sebuah kebutuhan perangkat lunak, bagaimana cara melakukan penilaian kebutuhan sebuah perangkat lunak dan perangkat lunak yang bagaimana yang dapat dinilai dengan metode yang ada. Pemodelan dilakukan berdasarkan hasil analisa sehingga pada akhirnya terbentuk sebuah model kebutuhan.

4. Evaluasi

Hasil penerapan kemudian akan dievaluasi kesesuaiannya dengan tujuan dari penelitian ini, dengan menganalisa dan mengevaluasi mekanisme untuk mendapatkan mekanisme yang tepat dalam menjawab rumusan masalah dalam penelitian ini. Proses validasi dan evaluasi akan dilakukan pada stakeholder $E$ commerce dan ukm di kota batam. 


\section{Hasil Dan Pembahasan}

\subsection{Analisa dan Pemodelan kebutuhan}

GORE Model akan digunakan untuk memodelkan kebutuhan E-commerce yang sesuai dengan untuk UKM. Untuk mendapatkan kebutuhan dari E-commerce yang akan dikembangkan, maka akan dijabarkan terlebih dahulu tujuan dari UKM. Berdasarkan hasil studi literatur [2] [3] [14] dapat disimpulkan bahwa tujuan dan faktor yang mempengaruhi keberhasilan UKM ada tiga, yaitu jual beli, pembinaan dan pembiayaan. Detail model kebutuhan E-commerce untuk ukm dapat dilhat pada gambar 3.

Jual beli merupakan salah satu tujuan utama UKM menggunakan E-commerce, berdasarkan penelitan dari Triandini et.al [13], tujuan jual beli dapat diturunkan menjadi beberapa sub-goal yaitu, memberikan informasi real-time kepada pelanggan, menambah dan memperbarui detail produk, mendukung komunikasi dengan pelanggan, mengelola akun, melakukan transaksi online, dan mendukung informasi dasbor untuk UKM. Untuk detail kebutuhanya tidak dijabarkan disini, karena fokus penelitian ini adalah pada tujuan pelatihan dan pembiayaan.

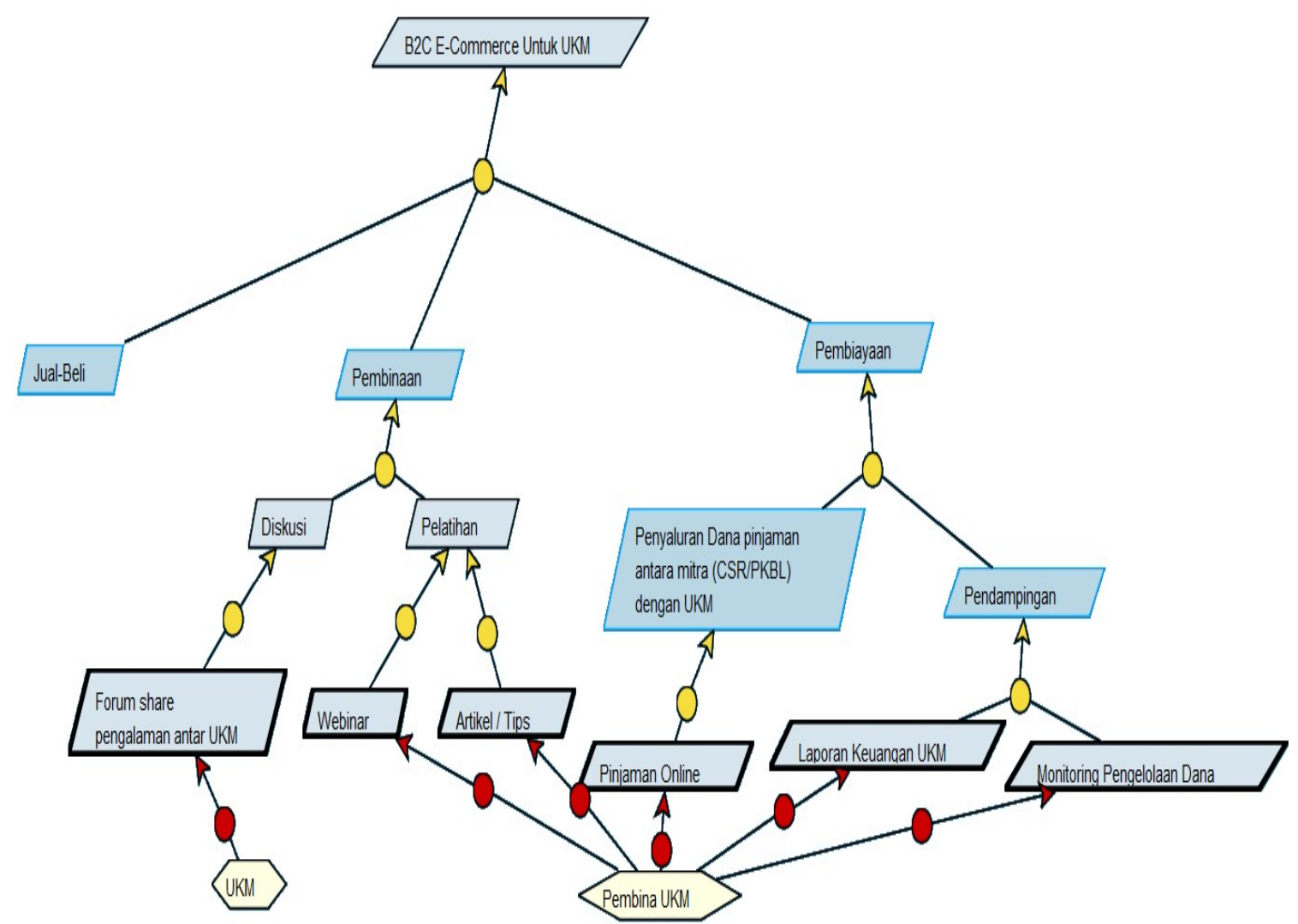

Gambar 3. Model Kebutuhan E-commerce untuk UKM

Pembinaan dapat diturunkan menjadi beberapa sub-tujuan yaitu, diskusi dan pelatihan. Diskusi dapat diturunkan menjadi kebutuhan akan adanya fitur forum diskusi antar UKM dan pembina, pada fitur ini UKM dapat melakukan diskusi dan berbagi pengalaman dan tips dalam menjalankan ukm-nya dengan diwadahi suatu forum. Sedangkan sub-tujuan pelatihan dapat diturunkan menjadi kebutuhan akan fitur webinar dan artikel yang diselenggarakan atau ditulis oleh pembina ukm. 


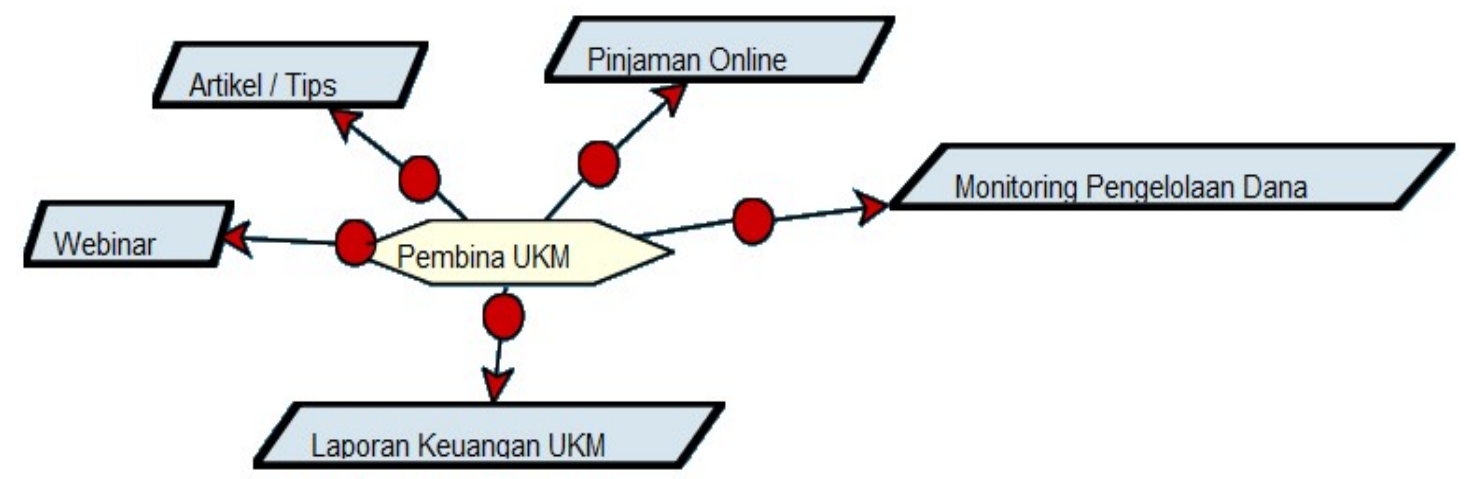

Gambar 4. Diagram tanggung Jawab agen pembina ukm

Pembiayaan dapat diturunkan menjadi beberapa sub-tujuan yaitu penyaluran dana pinjaman antara mitra (CSR/PKBL) dengan UKM dan pendampingan. Penyaluran dana pinjaman dapat diturunkan menjadi kebutuhan fitur pinjaman online, Sedangkan pendampingan dapat diturunkan menjadi fitur laporan keuangan dan monitoring pengelolaan dana. Fitur ini digunakan oleh pembina ukm untuk melakukan monitoring data keuangan dan penggunaan dana pinjaman yang telah disalurkan. Fitur ini juga dapat digunakan oleh pembina ukm dalam mengambil keputusan penyaluran dana/pinjaman kepada UKM binaanya.

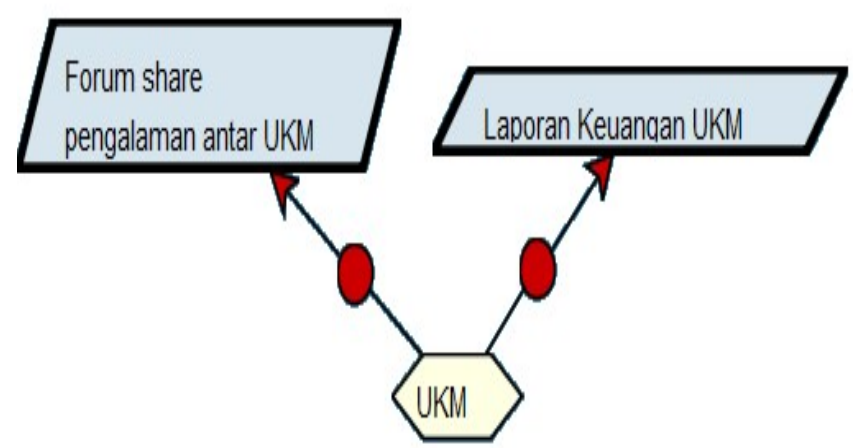

Gambar 5. Diagram tanggung Jawab agen ukm

Diagram tanggung jawab agen yang ditunjukkan pada gambar 4 dan 5 merepresentasikan tanggung jawab agen pada kebutuhan atau tujuan yang dimodelkan. Pembina UKM bertanggung jawab dalam menyelenggarakan kegiatan webinar, menulis artikel atau tips untuk ukm agar naik kelas, mencari skema pinjaman dan penyaluran dana untuk ukm, membuat format laporan keuangan dan melakukan monitoring pengelolaan dana yang disalurkan. Sedangkan UKM bertanggung jawab untuk menggunakan fasilitas forum sharing pengalaman antar ukm dan melakukan pelaporan keuangan secara rutin.

\subsection{Evaluasi}

Evaluasi model dilakukan dengan melibatkan pembina UKM center universitas universal dan 10 UKM binaanya. Untuk mengevaluasi model, pertama-tama kita mendefinisikan kebutuhan umum untuk E-commerce melalui studi lteratur dan wawancara dengan pembina UKM Center Universitas Universal dan UKM binaanya. Kebutuhan umum kemudian dimodelkan dengan menggunakan model generik KAOS. Model kebutuhan tersebut kemudian dianalisa dan diturunkan sehingga menghasilkan kebutuhan fungsional dan non-fungsional. Kebutuhan fungsional dan non-fungsional kemudian dinyatakan valid oleh pemangku kepentingan dari UKM Center Universitas Universal.

Oleh karena itu, hasil evaluasi menunjukkan bahwa model kebutuhan E-commerce untuk UKM dengan menggunakan KAOS terbukti digunakan dalam studi kasus sampai ia memberikan kebutuhan yang valid. 


\section{Kesimpulan Dan Saran}

Penelitian ini membahas tentang model kebutuhan perangkat lunak E-commerce yang sesuai untuk UKM. Pembuatan model diawali dengan melakukan studi literatur dan wawancara dengan UKM Center Universitas Universal sehingga menghasilkan tujuan (Goal) yang masih umum. Tujuan tersebut kemudian diturunkan menjadi beberapa sub-tujuan menggunakan pemodelan KAOS sehingga menghasilkan kebutuhan fungsional dan kebutuhan non-fungsional. Hasil penelitian ini memperkuat penelitian sebelumnya bahwa KAOS mempunyai kelebihan terutama dalam memberikan gambaran secara hierarki dari kebutuhan-kebutuhan yang ada dan lebih mudah untuk dilakukan penelusuran.

Evaluasi model dilakukan dengan menerapkan model pada UKM Center Universitas Universal dengan melibatkan pembina UKM center universitas universal dan 10 UKM binaanya. Dalam studi kasus, model ini mampu menghasilkan kebutuhan fungsional dan non-fungsional. Kebutuhan yang dihasilkan kemudian di validasi langsung oleh stakeholder, yaitu pembina UKM dan UKM binaan, hasilnya menunjukkan bahwa kebutuhan tersebut valid. Oleh karena itu hasil dari evaluasi menunjukkan bahwa pemodelan kebutuhan dengan menggunakaan KAOS dapat digunakan dalam memodelkan kebutuhan untuk aplikasi E-commerce yang sesuai dengan tujuan UKM dengan menghasilkan kebutuhan yang valid.

Namun dalam melakukan penurunan dan pemecahan tujuan, pemodelan menggunakan KAOS tidak memberikan prioritas pada sub-tujuan atau kebutuhan dan bagaimana menyelesaikan hambatan maupun konflik yang terjadi karena kurangnya metode pengukuran secara kuantitatif dan kualitatif.

Saran untuk penelitian selanjutnya adalah dengan melakukan penurunan kebutuhan dan goal dengan diperkuat perhitungan kuantitatif yang lebih nyata apakah sebuah kebutuhan memang dapat tercapai dengan sebuah alternatif tertentu atau bisa memunculkan alternatif lainnya, serta melakukan validasi apakah kebutuhan yang diturunkan masih memiliki halangan dari kebutuhan kepentingan pengguna.

\section{REFERENSI}

[1] Baum, David, 1999. E-commerce. New Jersey : oracle corp

[2] Hadi, S. A., Purnama, J., Amin Soetomo, M. A., \& Galinium, M. (2015). C2C E-commerce trust level measurement and analysis in Indonesia. Proceedings - 2014 6th International Conference on Information Technology and Electrical Engineering: Leveraging Research and Technology Through University-Industry Collaboration, ICITEE 2014. https://doi.org/10.1109/ICITEED.2014.7007900.

[3] RY, Novie Noordiana. "faktor-faktor yang memiliki kontribusi pada keberlangsungan dan kesuksesan umkm yang dikelola oleh kalangan usia muda." jurnal relasi stie mandala jember 13.1 (2017).

[4] Tsalgatidou, A., \& Pitoura, E. (2001). Business models and transactions in mobile electronic commerce : requirements and properties, 37, 221-236.

[5] Oliveira, T., Alhinho, M., Rita, P., \& Dhillon, G. (2017). Modelling and Testing Consumer Trust Dimensions in Ecommerce . Computers in Human Behavior. https://doi.org/10.1016/j.chb.2017.01.050

[6] Werneck, V. M. B., Oliveira, A. de P. A., \& do Prado Leite, J. C. S. (2009). Comparing GORE Frameworks: i-star and KAOS. Wer, (January), 1-12. Retrieved from http://wer-papers.googlecode.com/svn history/r71/trunk/dataset/wer09/WER09_4.pdf

[7] Horkoff, J., Ba, F., Cardoso, E., Li, T., Maté, A., Paja, E., Giorgini, P. (2016). Goal-Oriented Requirements Engineering: A Systematic Literature Map. https://doi.org/10.1109/RE.2016.41

[8] Eridaputra, H., Hendradjaya, B., Sunindyo, W. D., \& Gore, A. G. R. E. (2014). Modeling The Requirements for Big Data Application Using Goal Orieted Approach.

[9] van Lamsweerde, A. (2001). Goal-oriented requirements engineering: a guided tour. Proceedings Fifth IEEE International Symposium on Requirements Engineering, 249-262. https://doi.org/10.1109/ISRE.2001.948567

[10] M. Teruel, E. Navarro, and V. López-Jaquero, "Comparing Goal-Oriented Approaches to Model Requirements for CSCW," Evaluation of Novel Approaches to Software Engineering, pp. 169- 184, 2012

[11] Pachidi, Styliani. (2009). Goal-Oriented Requirement Engineering with KAOS. Utrecht University

[12] Hsia, T., Wu, J., \& Li, E. Y. (2008). Information \& Management The E-commerce value matrix and use case model: A goal-driven methodology for eliciting B2C application requirements, 45, 321-330. https://doi.org/10.1016/j.im.2008.04.001

[13] Triandini, E., Djunaidy, A., \& Siahaan, D. (2015). Determining E-commerce adoption level by SMEs in Indonesia based on customer-oriented benefits. 2014 1st International Conference on Information Technology, Computer, and 
Electrical Engineering: Green Technology and Its Applications for a Better Future, ICITACEE 2014 - Proceedings, 281-285. https://doi.org/10.1109/ICITACEE.2014.7065757

[14] Tangkary, S. (2016). Siap Menjadi Raja Digital Asean 
